Han Unbound 


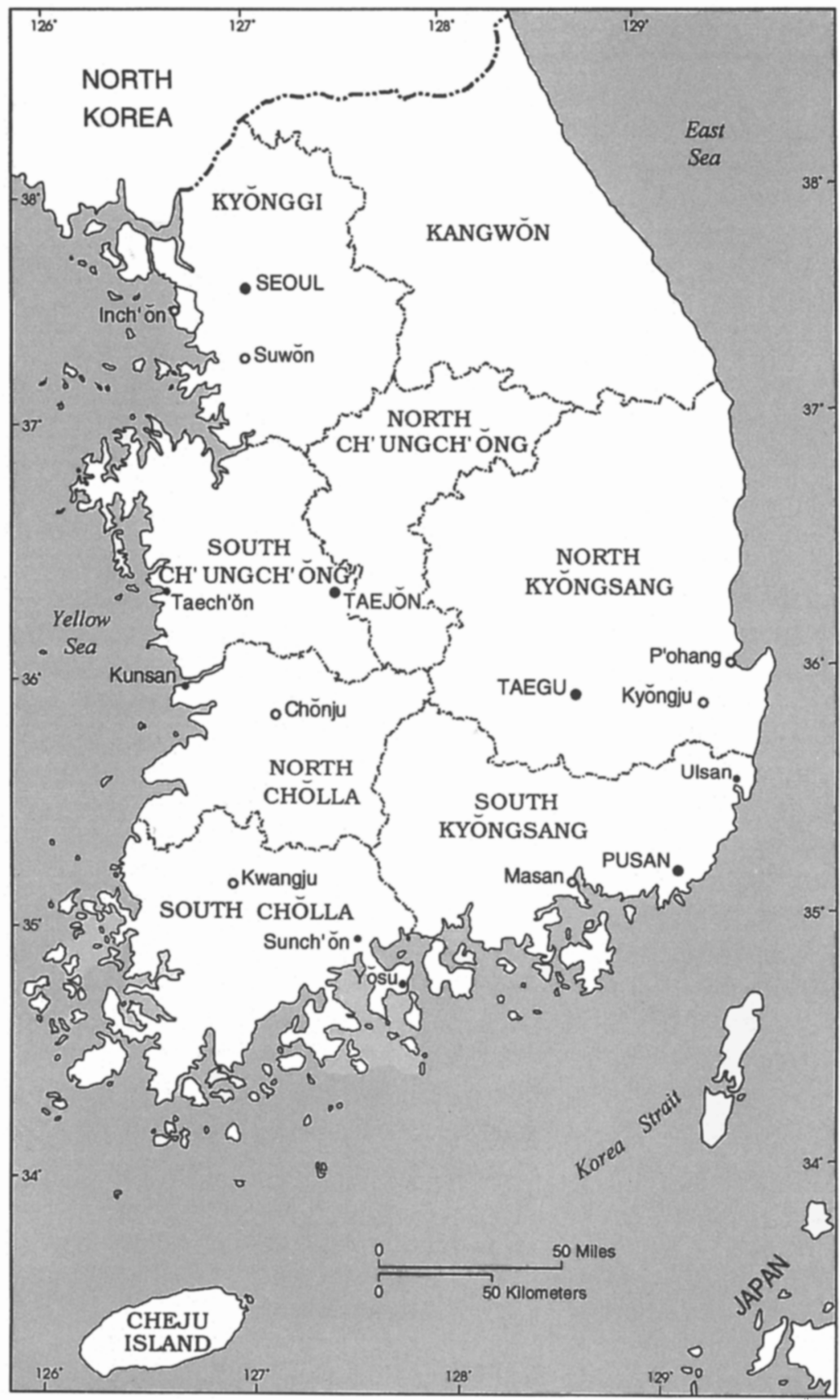

Present-day South Korea 


\title{
HAN UNBOUND
}

\author{
The Political Economy \\ of South Korea
}

sis

JOHN LIE

Stanford University Press

Stanford, California 
Stanford University Press

Stanford, California

(C) 1998 by the Board of Trustees of the

Leland Stanford Junior University

Printed in the United States of America

Book epigraph: Jorge Luis Borges, from "Epilogue,"

Oct. 3 I, 1960, in Dreamtigers, part II, trans. Harold Morland (C) I964).

Courtesy of the University of Texas Press.

CIP data are at the end of the book 
for Nancy Abelmann 
